\title{
Интернет-практики пожилых: 10 лет развития и изучения
}

\author{
И.А. Григорьева ${ }^{1}$ И.С. Петухова ${ }^{1,2}$ \\ ${ }^{1}$ Санкт-Петербургский государственный университет , \\ ${ }^{2}$ Петрозаводский государственный университет \\ Soc28@yandex.ru, irochka_kem@mail.ru
}

\section{Аннотация}

В статье представлено описание результатов исследований использования пожилыми современных информационно-коммуникативных технологий (ИКТ) и их влияние на социальное включение старшего поколения. Серия наших исследований (интернетисследования, вторичный анализ данных, телефонный опрос 500 жителей СанктПетербурга в 2017 году, многочисленные интервью и фокус-группы, проведенные в период 2008-2018 гг.) была направлена на изучение возможностей социального включения пожилых с помощью ИКТ, а также на использование ИКТ в оздоровлении, досуге, создании сообществ. Мы рассматривали использование ИКТ с разных сторон: как драйвер социального включения пожилых, ключ к получению новой занятости, но, как оказалось, использование ИКТ пожилыми стало престижной потребительской, досуговой, практикой. Основой социального включения остается занятость пожилых, как трудовая, так и общественная. Но занятость нуждается в имиджевой поддержке, не как вынужденная, а, наоборот, сохраняющая социальную включенность и интерес к жизни.

Ключевые слова: пожилые, ИКТ, включение, обучение, занятость, услуги, сообщество

Библиографическая ссылка: Григорьева И.А., Петухова И.С. Интернет-практики пожилых: 10 лет развития и изучения // Государство и граждане в электронной среде. Выпуск 3 (Труды XXII Международной объединенной научной конференции «Интернет и современное общество», IMS-2019, Санкт-Петербург, 19-22 июня 2019 г. Сборник научных трудов). - СПб: Университет ИТМО, 2019. С. 78 - 90. DOI: 10.17586/2541-979X-2019-3-78-90

\section{Введение}

В настоящее время внедрение информационно-коммуникационных технологий (ИКТ) и глобальное старение населения существенно меняют сложившиеся социальные структуры общества. О старении теперь принято писать, как о качественно новом, самобытном этапе жизни значительной длительности, но опыта рационального отношения и решения проблем стареющего общества пока очень мало $[1,2]$. Пожилые рассматриваются многими специалистами как растущая «группа риска» - vulnerability group, в отношении которой часто действуют практики исключения, обусловленные биологизированными и медикализированными взглядами на жизненный путь человека. С другой стороны, это типичная «номинальная группа», результат социального конструирования, весьма разнообразная и размытая по составу. Существующий набор стереотипов по отношению к пожилым людям в России не меняется уже много лет. Пожилые часто исключаются из общества и социально престижных сфер занятости под предлогом их неспособности овладеть информационными технологиями в ситуации, когда мир становится все более сложным коммуникационным комплексом. 
Развитие ИКТ и расширение доступа в Интернет вносит существенные коррективы в образ жизни современного пожилого человека [3, 4]. Мы изучали взаимодействие российских пожилых и общества, опосредованное использованием ИКТ, в течение почти пяти лет, реализуя проект РНФ. Использование ИКТ рассматривалось нами в нескольких аспектах. Во-первых, как драйвер социального включения пожилых [5], поскольку уже сложилась традиция рассматривать такое использование как приоритетную проблему. Очень важно было проанализировать обучение ИКТ как ключ к получению новой занятости, поскольку пожилых принято рассматривать как группу с неустойчивым положением на рынке труда $[6,7]$. Но, как оказалось, использование ИКТ стало одной из престижных потребительских практик, показателем «высокого досуга» тех пожилых, которые справились с обучением [8]. Были также попытки проанализировать, насколько использование ИКТ и интернета повлияло на улучшение качества жизни населения старшей возрастной группы [9], и формирование их сообществ $[10,11]$. Как мы уже отмечали, развивающийся концепт «информационного общества» фактически определил появление нового типа исключения - «информационно-коммуникационно-сетевого», который связан не только с недоступностью для некоторых частей общества технологических новинок, но также с отсутствием постоянно обновляемых знаний для их использования [12]. Одной из таких групп являются пожилые, багаж знаний которых обновляется медленнее, чем требует быстро меняющаяся «текучая действительность» [13].

Работа с гипотезой, что включение в мир ИКТ принципиально важно для социального включения пожилых, являлась вопросом ряда исследований и публикаций по их материалам по проекту. Обзор этой работы мы даем в предлагаемой статье.

Мы пришли к выводу, что для преодоления рассматриваемого типа исключения необходима переориентация социальной политики и общественного мнения, связанная с осознанием обществом и, что не менее важно, самими пожилыми людьми, идеи уважения к себе как к ресурсу общества, а не его ноше (burden) [14]. Для этого необходимо повышать уровень квалификации и занятости пожилых, ориентировать все слои общества на уважительное отношение к ним и отказ от эйджизма и самоэйджизма.

\section{1. Теоретическая рамка исследования}

«Социальное исключение / включение» - это сравнительно новая теоретическая рамка, пришедшая на смену традиционным иерархическим представлениям общества. Термин «социальное исключение» был введен французскими авторами для обозначения ситуации, в которой находятся социально-незащищенные группы населения [15]. Позднее эта концепция получила развитие как на Западе, так и в России. К социально незащищенным / социально исключенным стали относить те группы, которые по тем или иным причинам оказались лишены ресурсов, возможностей, прав для нормального существования в обществе. В современном стареющем обществе социальное исключение рассматривается как риск, связанный с разрывом социальных связей и отношений, нарушением процесса взаимодействия пожилых с обществом $[16,17]$.

В работах современных зарубежных авторов, социальное исключение рассматривается как «процесс, который включает в себя отсутствие или отказ в ресурсах, правах, товарах и услугах, по мере старения людей и неспособность участвовать в нормальных отношениях и деятельности, доступных большинству людей в различных и многочисленных областях общества. Это влияет как на качество жизни пожилых людей, так и на справедливость и сплоченность стареющего общества в целом [18].

С точки зрения современных отечественных и зарубежных авторов, социальное исключение в современном информационно-коммуникационном обществе может быть связано с отсутствием или низким уровнем навыков, определяющих включение пожилых в общество, в том числе, навыков ИК $[19,20,21,22]$. Доступ у пожилых людей к ИКТ и их использование, как правило, более ограничены, чем у других социальных групп. Некоторые 
ученые связывают это с тем, что ИКТ-грамотность не похожа на традиционную грамотность, возникает необходимость постоянно учиться чему-то новому; интерфейсы и приложения постоянно меняются. Современные западные исследования подтверждают положительное влияние образования, материальных ресурсов и социальных связей на ИКТвключение пожилых [22].

Социальное включение через обучение ИКТ можно считать, скорее, нормативной моделью взаимоотношения общества с пожилыми. Ряд авторов анализирует обучение пожилых ИКТ с точки зрения возможностей для включения их в общество. Однако многие авторы приходят к выводу, что обучение ИКТ пожилыми рассматривается не как способ продления занятости, а скорее, как активный досуг, что, в принципе, характерно для современного общества потребления [8]. Более традиционный взгляд связывает социальное включение с отношениями дружбы и соседства, т.е. возрастооднородными или разнопоколенными сообществами. Наши исследования интернет-сообществ пожилых показали, что «пожилые пользователи становятся участниками интересных для них сообществ, но не спешат устанавливать отношения «виртуальной дружбы» [18], онлайнсообщества формируются изначально в офлайн среде, а потом служат средством поддержания общения и обсуждения мероприятий [11]. Эти сообщества трудно назвать социальными, поскольку в них отсутствуют отношения взаимопомощи и возвратности/реципрокности.

\section{2. Описание методики}

Серия наших исследований (интернет-исследования, вторичный анализ данных, опрос жителей Санкт-Петербурга по случайной выборке в 2015 г. и телефонный опрос 500 жителей Петербурга по репрезентативной выборке в 2017 г., многочисленные интервью, наблюдения и фокус-группы, проведенные за период 2008-2018 гг.) была направлена на изучение возможностей социального включения пожилых с помощью современных информационно-коммуникационных технологий.

В этой работе мы прокомментируем данные некоторых наших исследований, полученные в течение 10 лет: сначала изучение информационных практик пенсионеров из России, Беларуси, Литвы, Дании и Швеции, 2009 год [23], которое послужило толчком к дальнейшему изучению темы; их сравнение с данными, полученными Агентством социальной информации (АСИ), 2008 год [24]; репрезентативный телефонных опрос 500 пожилых жителей С.-Петербурга, проведенный в 2017 году (выборка стратифицирована по полу и возрасту, сформирована и апробирована Ресурсным центром СПбГУ: «Центр социологических и Интернет-исследований» - http://rcsoc.spbu.ru/) и его сравнение с данными 4й волны RLMS) [25], многочисленные интервью в КЦСОН и библиотеках С.-Петербурга с преподавателями ИКТ и пожилыми, которых они обучали в 2014-2016 гг; а также автоматизированный веб-краулинг онлайн-сообществ пожилых ВКонтакте, 2018 г. [10, 11].

\section{3. Результаты исследования}

Первым для нас исследованием взаимодействия пожилых и ИКТ было сравнительное исследование доступа пожилых пяти стран к ИКТ и Интернету, проведенное в 2008 - начале 2009 гг. Мы рассмотрели связь процессов социального исключения пожилых и их информационных практик. В статье, освещавшей результаты исследований этих практик пенсионеров, было обработано 238 анкет из России, Беларуси, Литвы, Дании и Швеции (в выборку были включены только члены общественных организаций этих стран). Важно было выяснить, пользуются ли пенсионеры Интернетом и для чего именно. Оказалось, что спектр используемых возможностей довольно узок, а информационное неравенство может быть преодолено через обучение и активное участие самих пожилых пенсионеров в процессах 
коммуникации [26]. В Таблице 1 мы сравнили результаты этого исследования с более поздними данными.

Другие наши исследования (2014), также посвященные ИКТ-практикам пожилых, показывают, что растет использование е-почты, равно как использование сервиса «Скайп» и социальных сетей.

Таблица 1. Для чего используете доступ в Интернет [23, 24]

\begin{tabular}{|l|c|c|}
\hline \multicolumn{1}{|c|}{ Цели использования } & $\mathbf{2 0 0 9}$ & $\mathbf{2 0 1 4}$ \\
\hline Поиск информации & 19 & 84,4 \\
Чтение новостей & 5 & 68,8 \\
Переписка с друзьями по е-mail & 7 & 18,8 \\
Связь по Skyре с близкими друзьями или родственниками в других & 2 & 21,9 \\
городах/странах & & \\
Общение в социальных сетях: Vkontakte, Odnoklassniki, Facebook, Myspace, & 2 & 22,3 \\
Мушorld, etc. & 2 & \\
Чтение книг и периодики & - & 15,6 \\
Интернет-шоппигг & - & \\
Заказ номерков к врачу и др. медицинские услуги & 2 & - \\
Поиск дешевых туров или билетов и их заказ & 2 & - \\
Оплата телефона или коммунальных услуг & - & - \\
Перевод денег & - & 15,6 \\
Просмотр кино & 2 & 22,1 \\
Прослушивание радио & 1 & - \\
Использование услуг э-правительства & 1 & - \\
Другое & - & 18,1 \\
Ищу работу & 2 & - \\
Не ответили & & \\
\hline
\end{tabular}

Мы видим, что удобство е-почты и Скайпа оценено пожилыми и число пользователей этих сервисов за пять лет существенно выросло.

В 2014 году в рамках работы над проектом РНФ «Модели взаимодействия общества и пожилых людей: исследование возможностей социальной инклюзии» нами была проведена еще серия исследований, направленных на изучение информационно-коммуникативных практик пожилых. Одно из исследований проводилось в пунктах доступа в Интернет, оборудованных в почтовых отделениях Санкт-Петербурга. Проект организации Пунктов коллективного доступа в Интернет (ПКД) - всероссийский; это часть целевой программы «Электронная Россия». Суть проекта заключается в организации одного или нескольких рабочих мест в отделениях почтовой связи, оборудованных персональным компьютером, подключенным к сети Интернет. Основным методом сбора данных было невключенное наблюдение, оно было полевым и слабоструктурированным. Для сбора данных использовались также дневник и фотография. Согласно результатам нашего исследования, заявленная информация о развитии проекта доступа и реальность явно отличались друг от друга [27]. Пожилые редко пользуются ПКД, помощь в доступе к компьютерам им не всегда оказывается, а сами сотрудники почт не всегда понимают смысл этой программы. Для внедрения информационных услуг почты не была создана организационная основа, хотя в Белоруссии, где мы провели исследование в 2008 г., основной доступ у пожилых был именно на почтах [23]. Сегодня ПКД уже прекратили свое существование, во всяком случае, в Петербурге. Мы сделали вывод, что широкое включение пожилых в Интернет может быть обеспечено в массовых библиотеках города.

В 2016 мы продолжили наши исследования ИКТ-практик пожилых. Наши задачи заключались в оценке влияния новых технологий взаимодействия пожилых людей и общества (в частности, обучение компьютерной грамотности) на их социальную инклюзию [8]. Мы собрали 30 глубинных интервью и провели три фокус-группы. Основная гипотеза 
этой части исследования заключалась в том, что мотивация пожилых людей к обучению на курсах чаще всего связана с их желанием разнообразить досуг, освоить новую практику, не актуализируя для себя ее новые смыслы. Ниже представим основные результаты, которые нам удалось получить.

Первичным фактором приобщения людей старшего возраста к пользованию компьютером и Интернетом становится чувство одиночества и нехватки общения. Еще одна, с нашей точки зрения, распространенная цель обучения - абстрактное желание «все узнать». Совсем непопулярная мотивация - расширение профессиональных навыков и возможностей занятости. В первичном осваивании компьютера пожилым необходима помощь родственников, которые выступают посредниками между пожилым и компьютером, «настройщиком» программ. Многие навыки овладения компьютером осваиваются пожилыми людьми «методом тыка». Некоторым пожилым приходилось осваивать компьютер уже не рабочем месте. Однако, навыки, приобретенные на работе и необходимые дома, существенно различаются с точки зрения механики их освоения и предыдущего использования; это два совершенно разных способа и типа взаимодействия с ИКТ: узкоспециализированные программы с набором специальных задач - на рабочем месте и пользовательский опыт простых программ и приложений - дома. Важно отметить, что пожилые назвали некоторые трудности в освоении компьютера. В целом эти трудности связаны с освоением чего-то нового $[3,4,5]$.

Согласно проведенному в 2017 году телефонному опросу 500 пожилых (описание выборки выше), данные которого отражены в Таблице 2, не пользуются ни компьютером, ни Интернетом 28,5\% пожилых в Петербурге. Эта цифра представляется существенной, если брать повсеместное развитие ИКТ и хорошо организованный доступ к обучению пожилых ИКТ в Петербурге. Видимо, в «нестоличных» регионах число пользователей ниже. Очевидно, с возрастом количество «непользователей» увеличивается (преобладание женщин в старших возрастных группах только подтверждает данную динамику).

Таблица 2. Чем пользуются пожилые в Интернете

\begin{tabular}{|c|c|c|c|c|c|}
\hline Формулировки ответов & $\begin{array}{c}55 / 60-69 \\
\text { лет }\end{array}$ & $\begin{array}{c}70-79 \\
\text { лет }\end{array}$ & $\begin{array}{c}80 \text { и } \\
\text { старше }\end{array}$ & Мужчина & Женщина \\
\hline Затрудняюсь ответить & 2,2 & 1,2 & 0,0 & 2,1 & 1,4 \\
\hline $\begin{array}{l}\text { Не пользуюсь ни компьютером, } \\
\text { ни Интернетом }\end{array}$ & 28,5 & 55,0 & 76,7 & 37,1 & 46,2 \\
\hline $\begin{array}{l}\text { Ворд, Блокнот и другие } \\
\text { текстовые редакторы }\end{array}$ & 21,7 & 11,2 & 2,7 & 17,1 & 15,1 \\
\hline $\begin{array}{l}\text { Социальные сети } \\
\text { Одноклассники, } \\
\text { Фейсбук и т.д.) }\end{array}$ & 38,6 & 20,6 & 4,1 & 27,9 & 28,1 \\
\hline $\begin{array}{l}\text { Скайп или другие программы } \\
\text { для видеозвонков }\end{array}$ & 35,4 & 23,8 & 12,3 & 25,0 & 29,7 \\
\hline $\begin{array}{l}\text { Вайбер, Телеграм, Вотсап, } \\
\text { другие мессенджеры }\end{array}$ & 15,9 & 6,9 & 0,0 & 6,4 & 12,4 \\
\hline Электронная почта & 39,4 & 24,4 & 9,6 & 33,6 & 29,2 \\
\hline Ютуб или другие видеохостинги & 20,9 & 9,4 & 6,8 & 12,9 & 16,2 \\
\hline Новости, электронные СМИ & 43,0 & 24,4 & 6,8 & 35,0 & 30,8 \\
\hline $\begin{array}{l}\text { Скачиваю музыку, видео, } \\
\text { фильмы }\end{array}$ & 20,6 & 6,9 & 2,7 & 14,3 & 13,5 \\
\hline $\begin{array}{l}\text { Специализированные } \\
\text { программы для работы }\end{array}$ & 18,8 & 5,6 & 5,5 & 15,7 & 11,6 \\
\hline Играю в видеоигры & 11,2 & 5,0 & 0,0 & 7,1 & 7,8 \\
\hline Другое (запишите, что именно) & 4,0 & 6,2 & 4,1 & 4,3 & 4,9 \\
\hline $\begin{array}{l}\text { Затрудняюсь ответить, не хочу } \\
\text { отвечать }\end{array}$ & 0,4 & 0,6 & 0,0 & 0,0 & 0,5 \\
\hline
\end{tabular}


Наиболее востребованная «опция», предоставляемая ИКТ - доступ к новостям и электронным СМИ. Просмотр новостей отметили больше 1/3 ответивших. Исследование также подтверждает популярность использования электронной почты $(39,4 \%)$, социальных сетей $(38,6 \%)$, программ для видеозвонков $(35,4 \%)$.

В 2016-2017 гг., продолжая наше исследование, мы поставили задачу изучить, связана ли мотивация пожилых для обучения на предлагаемых государством курсах ИКТграмотности только с их желанием разнообразить досуг, освоить новую практику, не актуализируя при этом рациональные смыслы получаемых навыков [5]. Исследование проводилась в рамках множественного кейс-стади (case study). Как результат наших исследований, можем отметить, что большинство преподавателей в КЦСОН или библиотеках, с которыми мы проводили интервью, не имеют четкого представления об измерении эффективности услуг, которые они предоставляют. В качестве «обратной связи» выступают отзывы пожилых в сети «ВКонтакте», однако эти отзывы неконкретны. Качественная оценка услуг, предоставляемых пожилым, не формулируется даже как цель обучения. Однако важным является сам факт того, что государство обеспечивает возможность взаимодействия пожилых с современными технологиями, предполагая, что это влечет за собой их социальное включение.

Интересно также дополнить наши исследования другими данными, полученными в ходе разных опросов. Например, данными опроса ВЦИОМ о том, какова доля Интернетпользователей в России и для чего наши сограждане чаще всего заходят в глобальную сеть, проведенного в сентябре 2018 года (http://rcsoc.spbu.ru/) [26]. Согласно данным этого опроса, доля Интернет-пользователей в России составляет $81 \%$ населения в целом. Характеризуя частоту использования Интернета пожилыми (60 лет и старше), можно отметить, что 5\% проводят в глобальной сети более 4 часов ежедневно; почти треть опрошенных пользуются Интернетом ежедневно, меньше четырех часов в день; 10\% пожилых пользуются Интернетом несколько раз в неделю. Важно отметить также тот факт, что половина (!) опрошенных пожилых не пользуются Интернетом. Следовательно, в Санкт-Петербурге действительно большая, по сравнению со средней по России, часть пожилых, активно интернетом пользуется.

В то же время вовлеченности в пожилых в интернет во многих случаях мешают ограничения, связанные с удобством доступа. Для определения характера вовлеченности пожилых людей в социальные сети, в рамках того же проекта, нами было проведено собственное выборочное исследование на примере социальной сети ВКонтакте. С помощью поисковых возможностей самой социальной сети (поиск людей по параметрам) было замерено общее число аккаунтов, относящихся к России - таковых было найдено около 100 млн. Затем был добавлен параметр поиска «возраст от 55 до 80» - таких страниц оказалось около 2 млн, т.е. примерно $2 \%$ от общего числа российских аккаунтов ВКонтакте. После этого было проведено выборочное исследование 580 страниц из этих 2 млн, отобранных пошаговым методом, для проверки правдивости заявленной информации о возрасте. Анализировались личные фотографии, годы окончания школы и вуза - именно эти критерии были основными для подтверждения возраста автора страницы. В результате было выявлено, что половина из тех, кто указал возраст от 55 до 80 лет, являются «шутниками», - молодыми людьми, которые указали завышенный возраст. Но с другой стороны, минимум 34\% страниц выборки действительно оказались страницами людей в возрасте от 55 до 80 лет [30].

В качестве исследовательского метода было выбрано юзабилити-тестирование сайтов. Исследователями оценивалось наличие или отсутствие следующих параметров:

- удобство восприятия сайта: качественна ли графика и сочетается ли она с остальными составляющими страницы; на сайте используется анимация, реклама, отвлекающая от работы; на сайте используется хорошо читаемый шрифт; наличие версии для слабовидящих; 
- навигация: имеются ли на сайте основные способы навигации, удобство навигации; видны ли все способы навигации без прокручивания страницы, ... легко ли пользователи могут найти самые популярные (полезные) страницы на сайте, отражают ли самые популярные страницы сайта основные потребности пользовательской аудитории, возможность вернуться на главную страницу с второстепенных страниц, логична ли разбивка меню на блоки;

- дополнительный функционал: поиск по сайту, наличие инструкций, подсказок, возможность задать вопрос технической поддержке, онлайн поддержка.

Дизайн портала государственных и муниципальных услуг Санкт-Петербурга и Пенсионного фонда России достаточно удобен, с главных страниц можно найти необходимые услуги. Проблеме удобства для пожилых различных э-устройств, в том числе, мобильных приложений, были посвящены и специальные исследования [31].

Интересными также представляются данные, представленные ВЦИОМ, о популярности социальных сетей среди разных возрастных групп, отраженные в Таблице 3 [29]. Популярные социальные сети среди пожилых - Мой Мир - 14\% участников, Facebook - $13 \%$ и Одноклассники - $12 \%$.

Таблица 3. Есть ли у Вас аккаунты в следующих социальных сетях? Если да, то как часто Вы ими пользуетесь (вопрос задавался только пользующимся Интернетом, приведены ответы каждый / почти каждый день, \% от опрошенных в каждой группе)

\begin{tabular}{|l|c|c|c|c|c|c|}
\hline \multirow{2}{*}{ Возраст } & \multicolumn{7}{|c|}{ Пользователи } \\
\cline { 2 - 7 } & ВКонтакте & $\begin{array}{c}\text { Одноклас- } \\
\text { сники }\end{array}$ & Instagram & Google+ & Facebook & Мой Мир \\
\hline 18-24 года & 30 & 8 & 38 & 17 & 9 & 9 \\
25-34 года & 40 & 28 & 37 & 30 & 24 & 17 \\
35-44 года & 15 & 25 & 14 & 22 & 28 & 21 \\
45-59 лет & 12 & 27 & 9 & 24 & 26 & 39 \\
60 лет и & 3 & 12 & 2 & 7 & 13 & 14 \\
старше & 3 & & & & & \\
\hline
\end{tabular}

В контексте изучения степени связности пожилых через сетевое взаимодействие мы получили результаты изучения 21 онлайн сообщества людей старшего возраста в сети «ВКонтакте» образовательной, трудовой и досуговой направленности $[10,11]$. Исследование проведено на основе сетевого подхода с применением средств автоматизированного анализа данных, позволяющего оценить характеристики сообществ, а также процессы информационного обмена между участниками. Использован метод сетевого анализа данных, автоматизированный веб-краулинг онлайн-сообществ, а также программные пакеты Gephi и сервис анализа социальных сетей Socstat. C помощью качественного исследования контента, публикуемого в группах и мероприятий, проводимых в офлайн-среде, мы дополнили проведенный анализ.

Можно сделать вывод о формировании сообществ, которые характеризуются слабыми онлайн связями между пользователями групп людей старшего возраста в социальной сети «ВКонтакте». Результаты исследования показали, что в изученных группах реальное социальное сообщество формируется изначально в офлайн-среде, где происходят все ключевые мероприятия. Организаторы мероприятий используют площадки в социальных сетях как один из каналов информирования пожилых. Исследованием было обнаружено, что отсутствие пользовательской активности не приводит к распаду сообществ, а их численность, напротив, возрастает [9]. В то же время, интернет-сообщества трудно назвать социальными в собственном смысле слова, поскольку во взаимодействиях полностью отсутствуют такие существенные вещи, как реципрокность или попытки организации взаимопомощи. 
В 2017-2018г.г. году мы также провели большой блок исследований, посвященных взаимодействию пожилых и государственных социальных сервисов в рамках курса государства на трансформацию социального обслуживания пожилых. Исследование было проведено в пяти городах/регионах: Санкт-Петербург, Н. Новгород и область, В. Новгород и область, Петрозаводск, Томск. Основными эмпирическими материалами послужили полуструктурированные интервью с экспертами (руководителями центров социального обслуживания или их подразделений), нормативно-правовые акты различного уровня, статистические и демографические данные. Был сделан акцент на обслуживании на дому и не рассматривались стационарные формы обслуживании [31]. Исследование показало, что на практике либерализация заключается в существенном повышении платы за обслуживание и некотором послаблении в доступе к социальным услугам (обслуживание по месту пребывания вместо обслуживания по месту регистрации), а также в привлечении НГО/НКО в поле социального обслуживания. Но привлечение организаций 3-го сектора привело к необходимости каждой из них обзавестись доступным сайтом для информирования об оказываемых услугах и ответов на запросы пожилых, что также способствует вовлеченности пожилых в мир ИКТ.

\section{Выводы}

Современное поколение пожилых сильно отличается от предыдущих поколений не только высоким уровнем образования и уже имеющихся навыков, но и желанием, и квалификацией для продолжения профессиональной занятости и использования ИКТ. Обучение пожилых людей ИКТ за последние годы стало общероссийской практикой социальных служб и библиотек. Однако, наша гипотеза, что использование Интернета является, в первую очередь, престижной досуговой практикой, подтверждается.

Несмотря на наметившиеся положительные тенденции, проблемы доступа еще остаются: практически одна треть «молодых» российских пенсионеров не пользуются ни компьютером, ни Интернетом. Это, конечно, очень много с точки зрения приближения цифровой экономики, на фоне общедоступности компьютеров и обучению их использованию сегодня. Кроме того, значительная часть пожилых людей, не имеющих компьютерных навыков, вовсе не хочет обучаться и вполне довольна жизнью «без этих ваших компьютеров»... Нужна переориентация социума, связанная с осознанием обществом и, что не менее важно, самими пожилыми людьми, идеи уважения к себе как к peсурсу общества, а не его ноше (burden). Для этого необходимо повышать уровень квалификации и занятости пожилых, ориентировать все слои общества на уважительное отношение к ним и отказ от эйджизма и самоэйджизма.

Обычно пенсионеры пользуются ИКТ у себя дома или на работе. Пожилые предпочитают большие компьютерные устройства для выхода в Интернет. Выход в Интернет связан с несколькими потребностями: самая значительная из них - поиск новой информации и повышение уровня знаний. Что касается нового трудоустройства, то для реализации этой цели обучение использованию ИКТ служит пока недостаточно.

Поэтому дискурс «заботы», который мы начали развивать на последнем этапе проекта РНФ в связи с серьезными изменениями правового поля социального обслуживания, нужно переадресовать людям старше 70-75 лет, если исходить из того, что старение за последние 50 лет сдвинулось примерно на 15 лет. А для «молодых пожилых» - акцентировать необходимость развивать такие качества личности, как способность контролировать собственную жизнь и активно участвовать в трудовой и общественной жизни, в том числе, используя ИКТ.

Переходя с уровня эмпирических исследований на более теоретико-социологический, отметим, что широко распространенный технократический подход явно неэффективен при анализе проблем пожилых и, тем более, попыток их решения. В ситуации снижения социального статуса и потери жизненных ориентиров сводить проблемы пожилых к низкой 
пенсии и отсутствию навыков работы с современной техникой значит демонстрировать просто неуважение к ним. Но как убедить людей в том, что уход на пенсию перестал быть благом и является лишь первым шагом к социальному исключению и утрате смыслов жизни?

Для преодоления рассматриваемого типа исключения необходима переориентация социальной политики на продолжающих работать пожилых, но поддержание их здоровья и квалификации. То есть именно на тех, кто сам себя видит не заслужившим льгот пенсионером, а нормальным, экономически и социально независимым человеком.

Статья подготовлена на средства гранта РНФ 19-18-00246 «Вызовы трансформации социального государства в России: институциональные изменения, социальное инвестирование, цифровизация социальных услуг».

\section{Литература}

[1] United Nations. World Population Ageing 2017 - Highlights (ST/ESA/SER.A/397), New York: United Nations, 2017.

[2] Sidorenko A. 'Challenges and opportunities of population ageing in the CIS+ countries' // International Journal on Ageing in Developing Countries. 2016. Vol. 1 (1). P. 20-39.

[3] Akatsu H. Usability Research for the Elderly People // Oki Technical Review. 2004. Issue 199. Vol. 71, №.3. P. 54-57.

[4] Kerber N. Web Usability for Seniors // University of Baltimore. 2012. URL: http://home.ubalt.edu/nicole.kerber/idia612/Kerber_Literature_Review.pdf (дата обращения: 28.03.2015).

[5] Grigoryeva I., Shubinsky M., Mayorova E. ICT as a driver for senior citizens' social inclusion // ICEGOV 2014 - 8th International Conference on Theory and Practice of Electronic Governance. ACM International Conference Proceeding Series. P. 292-295.

[6] Григорьева И.А., Дмитриева А.В. Обучение пожилых ИКТ и возможности их трудоустройства // Технологии информационного общества в науке, образовании и культуре: сборник научных статей. Труды XVII Всероссийской объединенной конференции «Интернет и современное общество» (IMS-2014). СПб, 2014. С. 317-319.

[7] Коломиец П.Н. Дискриминация пожилых людей на рынке труда // Интернет-журнал «Науковедение». 2017. Т. 9, №5. URL: https://naukovedenie.ru/PDF/31EVN517.pdf. (дата обращения 07.06.2019).

[8] Григорьева И.А., Дмитриева А.В. Использование ИКТ как новая потребительская практика пожилых и качество их жизни // Государство и граждане в электронной среде: сборник научных статей. Труды XIX Международной объединенной научной конференции «Интернет и современное общество». СПб, 2016. С. 88-96.

[9] Дмитриева А.В. Социальное включение пожилых: продление занятости или «продвинутый» досуг? // Журнал исследований социальной политики. 2018. Т. 16, №1. C. $37-50$.

[10]Видясова Л.А., Григорьева И.А. Исследование влияния Интернет-сообществ на социальное включение пожилых людей посредством досуговых практик // Успехи геронтологии. 2018. Т. 31, №4. С. 597-603.

[11]Видясова Л.А., Григорьева И.А. Исследование возможностей социального включения пожилых через взаимодействие в онлайн среде (на примере сообществ в социальной сети «ВКонтакте») // Журнал социологии и социальной антропологии. 2018. Т. 21, № 2. C. $106-132$.

[12]Еляков А.Д. Информационный тип социального неравенства // СОЦИС. 2004. № 4. С. 95-101.

[13]Бауман 3. Текучая современность. Санкт-Петербург. Изд-во Питер. 2008. 
[14]Taylor P., Earl G. The Social Construction of Retirement and Evolving Policy Discourse of Working Longer // Journal of Social Policy. 2016. Vol. 45 (2). P. 251-68.

[15]Дмитриева А.В. Социальное включение/исключение как принцип структурации современного общества // Социологический журнал. 2012. № 2. С. 98-114.

[16]Григорьева И.А. Социальная политика и пожилое население в современной России: вызовы и возможности // Мир России. Социология. Этнология. 2006. Т. 15, №1. С. 29 49.

[17]Сапонов Д.И., Смолькин А.А. Социальная эксклюзия пожилых: к разработке модели измерения // Мониторинг общественного мнения: экономические и социальные перемены. 2012. №5 (111). С. 83-94.

[18]Walsh K., Scharf T., Keating N. Social exclusion of older persons: a scoping review and conceptual framework // European Journal of Ageing. 2017. №14. P.1-18.

[19]Видясова Л.А. Основные характеристики образовательных онлайн сообществ людей старшего возраста ВКонтакте // Государство и граждане в электронной среде. Выпуск 2 (Труды XXI Международной объединенной конференции «Интернет и современное общество, IMS-2018. Сборник научных статей). СПб: Университет ИТМО, 2018. С. 105111.

[20]Реутов Е.В., Колпина Л.В., Реутова М.Н. Социальные сети и повседневные практики населения Белгородской области // Социологические исследования. 2012, № 10 (342). С. 34-41.

[21]Печенкин В.В., Зайонц В.В. Сетевые методы исследования виртуальных сообществ // Теория и практика общественного развития. 2011. №5. С. 71-75.

[22]Loipha S. Thai Elderly Behavior of Internet Use // Procedia-Social and Behavioral Sciences. 2014. Vol. 147. P. 104-110.

[23]Olsson T., Samuelsson U., Viscovi D. At risk of exclusion? Degrees of ICT access and literacy among senior citizens // Information, Communication \& Society. 2019. Vol. 22 (1). P. 55-72. DOI: 10.1080/1369118X.2017.1355007.

[24]Григорьева И.А., Чернышова С.П. Новые подходы к профилактике социального исключения пожилых // Журнал социологии и социальной антропологии. 2009. Т. 12, № 2. C. $186-196$.

[25]Число интернет-пользователей в РФ в 2008 году вырастет на 30\%. 8 августа 2008. URL: https://ria.ru/20080808/150213079.html (дата обращения 07.06.2019).

[26]Григорьева И.А. и др. Старения больше не будет / И.А. Григорьева, Л.И. Сизова, Л.А. Видясова, А.В. Дмитриева, А.О. Парфенова, И.С. Петухова. СПб: Изд-во «Астерион». 2018.

[27]Григорьева И.А., Келасьев В.Н. Интернет в жизни пожилых: намерения и реальность // Социологические исследования. 2016. № 11 (391). С. 82-85.

[28]Просторы интернета: для работы или развлечений? // Всероссийский центр изучения общественного мнения. https://wciom.ru/index.php?id=236\&uid=9322 (6.06.2019).

[29]Бершадская Л., Биккулов А, Жук Д., Низомутдинов Б. Интернет и пожилые: включенность старших возрастных групп и внимание к их проблемам // Информационные ресурсы России. 2014. №5. С.11-15.

[30]Низомутдинов Б.А. Мобильные приложения электронного участия. Оценки и активность пользователей // Информационные ресурсы России. 2018. №4. С.63-64.

[31]Парфенова О.А. Трансформация социального обслуживания пожилых в региональном контексте современной России // Журнал социологии и социальной антропологии. 2018. № 2. C. $165-186$. 


\title{
Internet practices of the elderly: 10 years of development and study
}

\author{
Irina A. Grigoryeva ${ }^{1}$, Irina S. Petukhova ${ }^{1,2}$ \\ ${ }^{1}$ Saint-Petersburg State University, ${ }^{2}$ Petrozavodsk State University
}

The article describes the results of research on the use of modern information and communication technologies (ICT) by the elderly and their impact on the social inclusion of the older generation. A series of our studies (Internet research, secondary data analysis, telephone survey of 500 residents of St. Petersburg in 2017, numerous interviews and focus groups conducted in the period 2008-2018) was aimed at studying the possibilities of social inclusion of the elderly with the help of ICT, as well as the use of ICT in health, leisure and community building. We looked at the use of ICT from different perspectives: as a driver of social inclusion of the elderly, the key to new employment, but as it turned out, the use of ICT by the elderly has become a prestigious consumer, leisure, practice. The basis of social inclusion remains the employment of the elderly, both in the workplace and in the community. However, employment needs image support, not as forced, but on the contrary, preserving social inclusion and interest in life.

Acknowledgements. The study was performed with financial support by the grant from the Russian Science Foundation "Challenges of the transformation of Welfare State in Russia: institutional changes, social investment, digitalization of social services” (№19-18-00246).

Keywords: the elderly, ICT, inclusion, education, employment, services, community

Reference for citation: Grigoryeva I.A., Petukhova I.S. Internet practices of the elderly: 10 years of development and study // The State and Citizens in the Electronic Environment. Vol. 3 (Proceedings of the XXII International Joint Scientific Conference «Internet and Modern Society», IMS-2019, St. Petersburg, June 19-22, 2019). - St. Petersburg: ITMO University, 2019. P. 78 - 90. DOI: $10.17586 / 2541-979 X-2019-3-78-90$

\section{Reference}

[1] United Nations. World Population Ageing 2017 - Highlights (ST/ESA/SER.A/397), New York: United Nations, 2017.

[2] Sidorenko A. 'Challenges and opportunities of population ageing in the CIS+ countries' // International Journal on Ageing in Developing Countries. 2016, 1 (1): 20-39.

[3] Akatsu H. Usability Research for the Elderly People // Oki Technical Review. 2004. Issue 199. Vol.71. №.3.

[4] Kerber N. Web Usability for Seniors // University of Baltimore. 2012. Available at:: http://home.ubalt.edu/nicole.kerber/idia612/Kerber_Literature_Review.pdf, accessed 28 March 2015.

[5] Grigoryeva I., Shubinsky M., Mayorova E. ICT as a driver for senior citizens' social inclusion / 2014-January. ICEGOV 2014 - 8th International Conference on Theory and Practice of Electronic Governance - Proceedings. Cep. ICEGOV 2014. 8th International Conference on Theory and Practice of Electronic Governance - Proceedings. P. 292-295. Available at: https://www.scopus.com/authid/detail.uri?authorId=6507521314, accessed 7 June 2019.

[6] Grigoryeva I.A., Dmitrieva A.V. Obuchenie pozhilyh IKT i vozmozhnosti ih trudoustrojstva [ICT training and employment opportunities for older citizens] // Tekhnologii informacionnogo obshchestva v nauke, obrazovanii i kul'ture: sbornik nauchnyh statej. Trudy XVII Vserossijskoj ob"edinennoj konferencii «Internet i sovremennoe obshchestvo» (IMS2014) [Information society technologies in science, education and culture: collection of scientific articles. Proceedings of the XVII all-Russian joint conference "Internet and modern society"]. 2014. S. 317-319. (In Russian); 
[7] Kolomiec P.N. Diskriminaciya pozhilyh lyudej na rynke truda [Discrimination against older citizens in the labor market] // Internet-zhurnal «NAUKOVEDENIE» [Internet-journal "SCIENCE"]. Available at: https://naukovedenie.ru/PDF/31EVN517.pdf, accessed 7 June 2019. (In Russian).

[8] Grigoryeva I.A., Dmitrieva A.V. Ispol'zovanie IKT kak novaya potrebitel'skaya praktika pozhilyh i kachestvo ih zhizni [ICT use as a new consumer practice of elderly people, and their quality of life] // Gosudarstvo i grazhdane v ehlektronnoj srede: sbornik nauchnyh statej. Trudy XIX Mezhdunarodnoj ob"edinennoj nauchnoj konferencii «Internet i sovremennoe obshchestvo» [The state and the citizens in an electronic environment: a compilation of international articles. Proceedings of the XIX International joint scientific conference "Internet and modern society"]. 2016. S. 88-96. (In Russian).

[9] Dmitrieva A.V. Social'noe vklyuchenie pozhilyh: prodlenie zanyatosti ili «prodvinutyj» dosug? [Social Inclusion of Elderly People: continuation of employment or 'advanced' leisure?] // Zhurnal issledovanij social'noj politiki [The Journal of Social Policy Studies]. 2018. T. 16. №1. S. 37-50. (In Russian).

[10]Vidyasova L.A., Grigoryeva I.A. Issledovanie vliyaniya Internet-soobshchestv na social'noe vklyuchenie pozhilyh lyudej posredstvom dosugovyh praktik [Investigation Of InternetCommunities' Influence On The Social Inclusion Of The Elderly People Through Leisure Practices] // Uspekhi gerontologii [Advances in Gerontology]. 2018. T. 31. №4. S. 597-603. (In Russian);

[11]Vidyasova L.A., Grigor'eva I.A. Issledovanie vozmozhnostej social'nogo vklyucheniya pozhilyh cherez vzaimodejstvie $\mathrm{v}$ onlajn srede (na primere soobshchestv v social'noj seti «VKontakte») [Social Inclusion Of The Elderly Through Interaction In The Online Environment (The Case Of Online Communities In The Social Network "Vkontakte"] // ZHurnal sociologii i social'noj antropologii [Journal of Sociology and Social Anthropology]. 2018. T. 21. № 2. S. 106 - 132. (In Russian).

[12]Elyakov A.D. Informacionnyj tip social'nogo neravenstva [Information type of social inequality] // SOCIS [Socis]. 2004. № 4. S. 95-101. (In Russian).

[13]Bauman Z. Tekuchaya sovremennost' [Fluid modernity]. St. Petersburg, 2008. (In Russian).

[14]Taylor P., Earl G. (2016) The Social Construction of Retirement and Evolving Policy Discourse of Working Longer. Journal of Social Policy. 45 (2): 251-68.

[15]Dmitrieva A.V. Social'noe vklyuchenie/isklyuchenie kak princip strukturacii sovremennogo obshchestva [Social inclusion/exclusion as a principle of structuring modern society] // Sociologicheskij zhurnal [Sociological journal]. 2012. №2. S. 98-114. (In Russian).

[16]Grigoryeva I.A., Social'naya politika i pozhiloe naselenie v sovremennoj Rossii: vyzovy i vozmozhnosti [Social policy and elderly population in modern Russia: challenges and opportunities] // Mir Rossii. Sociologiya. Etnologiya [World of Russia. Sociology. Ethnology]. 2006. T. 15 №1. S. 29-49. (In Russian).

[17]Saponov D.I., Smol'kin A.A. Social'naya eksklyuziya pozhilyh: k razrabotke modeli izmereniya [Social exclusion of the elderly: towards the development of a measurement model] // Monitoring obshchestvennogo mneniya: ekonomicheskie i social'nye peremeny [Public opinion monitoring: economic and social changes]. 2012. №5 (111). S. 83-94. (In Russian).

[18]Walsh, K., Scharf, T., \& Keating, N. Social exclusion of older persons: a scoping review and conceptual framework. European Journal of Ageing. 2017, №14, P.1-18.

[19]Vidyasova L.A. Osnovnye harakteristiki obrazovatel'nyh onlajn soobshchestv lyudej starshego vozrasta VKontakte [The main characteristics of the educational online communities of older people Vkontakte] // Gosudarstvo i grazhdane v elektronnoj srede [State and citizens in the electronic environment]. 2018, №2. S. 105-111. (In Russian).

[20]Реутов Е.В., Колпина Л.В., Реутова М.Н. Социальные сети и повседневные практики населения Белгородской области // Социологические исследования. 2012, № 10 (342). С. $34-41$. 
[21]Reutov E.V., Kolpina L.V., Reutova M.N. Social'nye seti i povsednevnye praktiki naseleniya Belgorodskoj oblasti [Social networks and everyday practices of the population of the Belgorod region] // Sociologicheskie issledovaniya [Sociological research]. 2012, № 10 (342). S. 34-41. (In Russian).

[22]Loipha S. Thai Elderly Behavior of Internet Use // Procedia-Social and Behavioral Sciences. 2014, 147. P. 104-110.

[23]Tobias Olsson, Ulli Samuelsson \& Dino Viscovi (2019) At risk of exclusion? Degrees of ICT access and literacy among senior citizens, Information, Communication \& Society, 22:1, P. 55-72, DOI: 10.1080/1369118X.2017.1355007.

[24]Grigoryeva I.A., CHernyshova S.P. Novye podhody k profilaktike social'nogo isklyucheniya pozhilyh [New approaches to prevention of social exclusion of the elderly] // ZHurnal sociologii i social'noj antropologii [Journal of Sociology and Social Anthropology]. 2009. T. 12. № 2. S. 186-196. (In Russian).

[25]CHislo internet-pol'zovatelej v RF v 2008 godu vyrastet na 30\%. 8 avgusta 2008 [The Number of Internet users in Russia will grow by $30 \%$ in 2008. August 8, 2008]. Available at: https://ria.ru/20080808/150213079.html, accessed 7 June 2019. (In Russian).

[26]Grigoryeva I.A. i dr. Stareniya bol'she ne budet [Aging will no longer] / I.A. Grigoryeva, L.I. Sizova, L.A. Vidyasova, A.V. Dmitrieva, A.O. Parfenova, I.S. Petuhova. St. Petersburg. Izdatel'stvo «Asterion», 2018. (In Russian).

[27]Grigoryeva I.A., Kelas'ev V.N. Internet v zhizni pozhilyh: namereniya i real'nost' (Internet in the life of elderly people: intentions and realities) // Sociologicheskie issledovaniya [Sociological Studies]. 2016. № 11 (391). S. 82-85. (In Russian).

[28]Prostory interneta: dlya raboty ili razvlechenij? [Open spaces of the Internet: for work or entertainment?] // Vserossijskij centr izucheniya obshchestvennogo mneniya [All-Russian center for public opinion research]. Available at: https://wciom.ru/index.php?id=236\&uid=9322, accessed 6 June 2019. (In Russian).

[29]Bershadskaya L., Bikkulov A, ZHuk D., Nizomutdinov B. Internet i pozhilye: vklyuchennost' starshih vozrastnyh grupp i vnimanie $\mathrm{k}$ ih problemam [Internet and the elderly: inclusion of older age groups and attention to their problems] // Informacionnye resursy Rossii [Information resources of Russia]. 2014. №5. S.11-15. (In Russian).

[30]Nizomutdinov B.A. Mobil'nye prilozheniya elektronnogo uchastiya. Ocenki i aktivnost' pol'zovatelej [Mobile application of e-participation. Ratings and user activity] // Informacionnye resursy Rossii [Information resources of Russia]. 2018. №4. S.63-64. (In Russian).

[31]Parfenova O.A. Transformaciya social'nogo obsluzhivaniya pozhilyh $\mathrm{v}$ regional'nom kontekste sovremennoj Rossii [Transformation of social services for the elderly in the regional context of modern Russia] // ZHurnal sociologii i social'noj antropologii [The Journal of Sociology and Social Antropology]. 2018. № 2. S. 165 - 186. (In Russian). 